\title{
PUTA, VAGABUNDA E ESPOSA: UMA ANÁLISE SOBRE A OPRESSÃO PATRIARCALISTA CONJUGAL
}

\section{Giseliane Medeiros Almeida ${ }^{1}$ \\ Maria Helena Santana Cruz ${ }^{2}$}

Resumo: Este artigo problematiza a opressão patriarcalista conjugal, objetivando discutir acerca do labiríntico papel da mulher casada inscrito no imaginário social atual. A metodologia utilizada é a qualitativa com ênfase em estudo de caso, entrevista semiestruturada realizada com três mulheres casadas prisioneiras; e a técnica de análise é o discurso, mediante uma análise entre o público e o privado que se organizam, no primeiro momento, com base nas falas das entrevistadas discutindo sobre os modelos atribuídos às muIheres (santas e putas). A conclusão é a denúncia de que a opressão e a violência patriarcalista, como uma herança histórica, ainda são vivenciadas pelas mulheres casadas nos entrelaces das emoções, amor e dependências.

Palavras-Chave: Mulher; Opressão; Patriarcalismo.

Abstract: This article discusses patriarchal marital oppression, aiming to discuss the labyrinthine role of married women enrolled in the current social imaginary. We use the qualitative methodology with emphasis on case study, semi structured interview with three married women prisoners; and the technique of discourse analysis. An analysis between the public and the private that is organized in the first moment based on the statements of the interviewee discussing the models attributed to women (saints and whores). It concludes by denouncing oppression and patriarchal violence as a historical heritage, which married women still experience in the intertwining of emotions, love, and dependencies.

Keywords: Woman. Oppression. Patriarcalism.

\section{Introdução: A construção dos gêneros}

Na sociedade atual existe um embate no que se refere ao "modelo ideal" de ser mulher. Durante décadas, os movimentos feministas lutaram por espaço e têm alcançado contribuições significativas no seio social, político e cultural, contudo, ainda perdura uma ideologia patriarcal dominante que dita modelos de ser

\footnotetext{
1 Mestre em Educação pela Universidade Federal de Sergipe. Professora do curso de Pedagogia da Faculdade Pio Décimo. Professora substituta da Universidade Federal de Alagoas. E-mail: <gisele_ufal@hotmail.com>.

2 Doutora em Educação pela Universidade Federal da Bahia. Professora da Universidade Federal de Sergipe. E-mail: <helenacruz@uol.com.br>.
} 
e viver a condição de mulher na sociedade.

Essa ideologia foi construída ao longo do tempo por meio da educação formal e informal que atribui significados para comportamentos masculinos e femininos, bem como o papel de cada um na sociedade. Esta análise pode ser percebida entre os entrelaces da história do século XX e início do século XXI, ocasião em que autores destacam a educação escolar diferenciada destinada às mulheres (âmbito privado) e homens (domínio público), assim como uma educação informal precedida de concepções religiosas, políticas e culturais que impõe formas "adequadas" para que a mulher se comporte socialmente.

Nesse sentido, este artigo objetiva analisar discursos de mulheres em torno da vida conjugal, problematizando as múltiplas violências sofridas por elas no entrelace de amor e de várias formas de dependência, contextualizando-os à categoria de gênero e educação.

Busca-se refletir acerca de padrões estereotipados com relação ao papel de esposa, em um imaginário social machista que lhe impõe a subserviência ao homem; para tanto é utilizada a perspectiva teórico-metodológica a fim de pensar sobre as análises de discursos de mulheres do interior de Alagoas que vivem, diariamente, em situação de opressão pelos seus companheiros. A análise aqui proposta diz respeito às inquietações do cotidiano, trazendo à luz um estudo de caso específico que pode refletir o que uma parte considerável de mulheres casadas vivem ou já viveram.

Algumas questões de pesquisa são traçadas, como por exemplo: como vivem as mulheres casadas do século XXI? Ainda há normas de condutas e comportamentos considerados adequados? Qual relação se estabelece entre gênero, educação e violência conjugal?

Considera-se o estudo relevante na medida em que se pretende fazer uso de métodos de análise consistentes, pensando no imaginário social atual de ser mulher, os modelos postos (santas e putas), situações de subordinação e dependência vivenciadas, assim como possibilidades de libertação feminina por meio do empoderamento ${ }^{3}$ e sororidade ${ }^{4}$, uma vez que o feminismo, aqui descrito, centra-se na necessidade de abarcar todas as mulheres em suas especificidades, em uma relação de companheirismo e luta diária contra o patriarcado e subordinação, em prol de igualdade de direitos e respeito/valorização das diferentes formas de ser e viver sua condição de mulher.

Ressalta-se a necessidade de pensar um feminismo acadêmico que se expan-

\footnotetext{
3 "É entendido como uma série de atitudes que levam a uma valorização e autorreconhecimento do 'ser mulher'. O empoderamento não é concedido, mas passa pela autoconsciência das pessoas e ganha voz através da atuação de vários grupos como na Marcha do Empoderamento Crespo ou na reafirmação do orgulho LGBTTQI (Lésbicas, Gays, Bissexuais, Transsexuais, Travestis, Queer e Intersexo)". (MARQUES, 2018, s/p).

4 "É uma expressão designada para narrar a cumplicidade, empatia e apoio mútuo entre as mulheres. $\bigcirc$ que se busca é uma cooperação em torno de um bem comum. A palavra vem da noção de irmandade entre as mulheres sem nenhum clima de disputa". (MARQUES, 2018, s/p).
} 
da para as realidades locais e globais. Neste artigo, a proposta é debater acerca do discurso de uma mulher constituindo este em uma amostragem e problematização da pesquisa. Considerando que as vozes de mulheres e impulsos de luta surgem de situações de opressão vivenciadas na condição de um ato de resistência, mulheres que lutam em meio a uma sociedade que ainda é extremamente masculina ${ }^{5}$ e patriarcalista em herança a educação modelista vivenciada a décadas.

\section{Caminhos Metodológicos}

Compreende-se que o método de pesquisa é o que a constitui e dá caráter científico ao objeto que se propõe a estudar. Nesse sentido, corrobora-se com Prost (2014), quando este apresenta a necessidade de uma reflexão crítica dos dados, bem como a importância de questionar e buscar respostas plausiveis com base em formas de interpretação pertinentes. Para tanto, é necessário que haja, além de um amadurecimento teórico, formas de organização da pesquisa e cuidados com as manipulações e movimento embaraçoso dos jogos políticos.

Dessa forma, é utilizada como norte a epistemologia pós-crítica em educação que é um campo aberto e flexivel e proporciona caminhos entre várias áreas do saber, a fim de construir o conhecimento de maneira pertinente, duvidando das verdades absolutas e abrindo leques de possibilidades de interpretação e análise dos dados, de acordo com o tempo e espaço em que são produzidos.

O/a pesquisador/a que trabalha com a perspectiva pós-crítica precisa estar em constante movimento para a construção de um saber diferenciado, considerando que se encarrega "[...]do já feito e sabido sobre o nosso objeto para suspender verdades [...]. Participamos da tradição do nosso objeto porque necessitamos saber o que já foi produzido, para analisar, interrogar, problematizar e encontrar outros caminhos". (MEYER; PARAÍSO, 2012, p. 35).

Não é pretensão, por meio deste trabalho, buscar respostas ou únicas verdades, mas há uma preocupação em descrever e problematizar processos por meio dos quais significados e saberes específicos são produzidos no contexto de diferentes redes de poder, indivíduos, grupos sociais, politicos e culturais (MEYER;

\footnotetext{
5 Aqui prefere-se utilizar "patriarcalismo" e não "patriarcado", afim de rechaçar as posições estática que nos levam a pensar em uma estrutura de opressão autônoma quanto ao resto de opressões e dominações que preponderam nas relações sociais capitalistas.

p patriarcado só afeta a um determinado coletivo (a mulher em abstrato). $\bigcirc$ patriarcalismo, por sua vez, é uma categoria que abarca o conjunto de relações que articulam um conjunto de opressões: gênero, sexo, etnia, classe social e orientação sexual, assim como o modo em que as relações sociais particulares se conjugam em uma dimensão pública de poder, exploração e submissão pessoal. O termo patriarcalismo é mais adequado porque nos faz ver como as relações de patriarcais se articulam com outras formas de relação social em um momento histórico dado. Isto porque as estruturas de classe, racismo, gênero e sexualidade não podem ser tratadas como variáveis independentes, pois, a opressão de cada uma está imbricada na outra. Ou seja, vivemos em uma ditadura de comportamentos, em meio às nossas vivências diárias, não é preciso se esforçar para perceber essa ditadura, que dita modelos de como ser "um cidadão correto", entretanto, este cidadão "modelo/padrão/bonito/tradicional" advém de um contexto histórico Europeu, que padroniza o homem branco, de cabelos lisos, heterossexual, magro, etc., como o modelo de beleza e moral social.
} 


\section{PARAÍsO, 2012, p. 56).}

Procurou-se, também, delinear os caminhos com os quais a pesquisa foi realizada, pautando-se na epistemologia pós-crítica, sob uma metodologia qualitativa, com observação participante, entrevistas semiestruturadas e análise textual discursiva.

Com ênfase na metodologia qualitativa, realizou-se a pesquisa por meio do estudo de caso realizado com a amostragem relativa a relatos de três mulheres casadas e prisioneiras de um presidio no interior de Alagoas, buscando estabelecer uma ponte entre universalidade e contexto social, considerando como alternativa a evidência de explorar o objeto da pesquisa de maneira a pensar sobre o que ele revela a respeito do todo. Conforme Ventura (2007), o estudo de caso observa que é preciso ter cuidado, uma vez que "[...] deverá haver sempre a preocupação de se perceber o que o caso sugere a respeito do todo e não o estudo apenas daquele caso. Portanto, pesquisar significa fazer uma escolha, pois em cada caso concreto, deve-se definir um determinado nivel de agregação." (VENTURA, 2007, p. 383).

Meirinhos e Osório (2010, p. 54) sobre o estudo de caso revelam que:

[...] o seu valor reside em que não apenas se estuda um fenómeno, mas também o seu contexto. Isto implica a presença de tantas variáveis que o número de casos necessários para as tratar estatisticamente seria impossivel de estudar. Outra temática relacionada com os estudos de caso é a sua capacidade para poder fazer generalizações. Na opinião de Stake (1999), a finalidade dos estudos de caso é tornar compreensivel o caso, através da particularização.

A pesquisa aqui descrita utiliza uma amostragem de discursos particulares em seu contexto relacional em prol de pensar na perspectiva de reflexões que auxiliem em visões culturais, nas quais as entrevistadas encontram-se inseridas.

A coleta de dados foi feita através de entrevista semiestruturada, realizada com três mulheres casadas do interior de Alagoas, fornecendo dados que revelam inúmeras formas de violência patriarcal conjugal.

A análise do discurso permite ao pesquisador entender e interpretar as múltiplas verdades, os sentidos do discurso do sujeito, a partir de sua realidade, de sua história de vida e de suas experiências intersubjetivas.

Foucault (2009, p. 9) defende que:

[...] em toda sociedade a produção do discurso é ao mesmo tempo controlada, selecionada, organizada e redistribuída por certo número de pro- 
cedimentos que têm por função conjurar seus poderes e perigos, dominar seu acontecimento aleatório, esquivar sua pesada e terrivel materialidade.

Assim, os discursos possuem poder extraordinário, que vão além das simples palavras, podendo reproduzir ideologias dominantes, bem como denunciá-las. Cabe ressaltar que discursar não diz respeito a verdades ou falsidades, pois a verdade é construída por cada um em seu discurso, ou seja, a verdade vai se redigir no que diz o discurso no momento e no espaço em que se fala. Sendo assim, diante dessa situação, o indivíduo vai obter o que Foucault (2009) chama "vontade de verdade", que nunca cessa, mas apenas se transforma.

Concomitantemente, por meio das técnicas de coleta e análise dos dados considera-se a pesquisa aqui descrita pertinente, na medida em que se reporta à elaboração de um estudo que intercala a teoria e a prática como condicionantes do processo de reflexão em torno das violências sofridas por mulheres casadas em meio à dor, sofrimento, amor e dependências.

\section{O Ideal de Ser Mulher: Santas ou Putas?}

A pesquisa de campo realizada aponta para a necessidade de pensar nos estigmas atrelados à mulher e quais cobranças e violências elas sofrem dentro de suas próprias casas. O título do artigo referente a "puta, vagabunda e esposa" é fruto do discurso de uma dessas mulheres, proporcionando uma reflexão sobre o que é ser puta na sociedade atual e como surgiram esses padrões e imagens atrelados às mulheres.

De acordo com Follador (2009), ao longo da história percebe-se que o olhar masculino (daquele que escreveu a história) atribuía às mulheres imagens diferentes, como por exemplo, a imagem de Eva, que denegriria a imagem da mulher e a de Maria, uma santa e mãe zelosa, que deveria ser alcançada por toda mulher honrada e de familia.

Louro (2008), em História das mulheres no Brasil, também relata a dicotomia entre Eva e Maria associada às mulheres. $\mathrm{Na}$ época da proclamação da $\mathrm{Re}$ pública, embora houvesse a separação entre igreja e Estado, a referência para a mulher era o catolicismo, permanecendo dominante a moral religiosa atribuindo modelos de ser mulher. Esse ideal da mulher santa, virgem, mãe e dona de casa é um discurso que, de acordo com Louro (2008, p. 446; suprimimos), é hegemônico no que se refere à história da educação das mulheres, as quais deveriam ser: "[...] mais educadas do que instruídas, ou seja, para elas, a ênfase deveria recair sobre a formação moral. [...] não havia porque mobilizar a cabeça da mulher com informação ou conhecimentos, já que seu destino primordial como esposa e mãe - [...] educadora do futuro".

Desse modo, havia um currículo escolar diferenciado destinado às mulheres, 
no que se refere ao desenvolvimento de habilidades relacionadas ao bordado, culinária, moralidade, dentre outras, que tinha como objetivo manter a mulher no seu "lugar" de subordinação e papel social que lhe era atribuído.

Nesse sentido, discursos das entrevistadas tornam-se labirínticos, na medida em que - apesar delas serem esposas e cuidarem da casa e do marido -, eles utilizam padrões e modelos para exercerem o poder atrelado ao homem da família, como é perceptível na fala da entrevistada transcrita a seguir: "Sua puta, vagabunda, nunca será nada na vida, gorda, cheia de estrias, burra... Gritos sem fim encravados na minha mente." (ROSA $\left.{ }^{6}\right)$.

Supõe-se que o marido profere palavras como gorda e burra, na perspectiva de manter o seu bem junto a ele, uma vez que, assim como afirma Saffioti (1987), a construção social da supremacia masculina exige a construção da subordinação feminina; "[...] mulher inferior é a outra face da moeda do macho superior" (p. 29). Subentende-se que, ao tratar a mulher com palavras ofensivas, o homem possui o objetivo de manter o seu poder patriarcalista, ou seja, uma educação informal que condiciona a mulher a seu papel histórico atrelado à submissão.

Nesse contexto, convida-se a refletir sobre o que é ser puta, vagabunda e esposa na sociedade atual, uma vez que a mídia ainda reproduz os estereótipos de mulher ideal para o casamento, e aquelas que são destinadas apenas ao bel prazer dos machos dominantes; ambas se submetendo ao domínio masculino.

Corrobora-se com Saffioti (1987), quando afirma que: “[...] enquanto 'santas' e 'prostitutas' continuarem a representar os papéis que a hipócrita sociedade burguesa lhes atribui o status quo, o estado de coisas presentes encontra suporte para se manter intacto, incólume, intocável" (p.32).

Nessa perspectiva, prosseguindo na análise de discurso de uma das entrevistadas, Girassol afirmou que é muito feliz com o seu marido e que ele é muito bom, que sempre teve de tudo, mas que possui um lado que queria muito combater, pois a incomoda, e assim começa a contar a sua história de vida diária,

Eu não faço nada que o deixe chateado, quando estava estudando era de casa para a faculdade, nunca gostei de festas nem de safadeza, mas quando ele se zanga com alguma coisa sempre desconta em mim, ele arranja um motivo de me machucar, parece que sou um saco de pancadas. Por qualquer motivo (parece mentira, mas é verdade eu juro!) Ele começa a gritar muito me chamando de brocada, ele já até me bateu, mas só foi uma vez, e me expulsou de casa de madrugada, já passou uma viagem inteira gritando com toda a força dentro do carro com as janelas travadas. Já passei noites inteiras chorando e dormindo no chão, pois ele não permitia que eu dormisse na cama, eu nunca entendi o por que dele me tratar assim, será que

$6 \quad$ Foram utilizados nomes fictícios para resguardar a identidade das entrevistadas assim como assinalado no Termo de Consentimento Livre e Esclarecido- TCLE, assinados pelas pesquisadas e pela pesquisadora. 
é normal casar para ser infeliz e apenas ouvir? Por vezes fiquei me perguntando se era justo e o que tinha feito para merecer tudo isso e nunca cheguei em nenhuma resposta. Mas ele não é assim tão ruim, sabe, tem os momentos bons em que ele sai comigo, nós viajamos as vezes e se conversar direitinho posso até sair sozinha de dia com algumas amigas, mas tem que ser em uma lua boa. (GIRASSOL).

Diante desse discurso, é possivel perceber o quanto a subordinação e sentido de inferioridade estão presentes na fala de Girassol, mesmo ela falando que ele a machuca, sempre volta a dizer que é feliz e se conforma com algumas coisas, as quais considera positivas. Em uma frase ela se pergunta: "será que é normal casar para ser infeliz?" Saffioti (1987), em suas análises, afirma que - historicamente - a função da mulher é ser infeliz, considerando o caráter biológico e educacional atribuído a sua função social.

Rosaldo (1979) ressalta que o caráter universal da autoridade masculina e desigualdade sexual, mesmo em meio às variações sociais existentes, propõe pensar nas implicações acerca do público e privado, locais em que, historicamente, a mulher é colocada na condição de um ser "natural" definida pela biologia como mãe propulsora de espaço doméstico enquanto ao homem cabe o espaço público, trazendo à tona os fatores que tornam a mulher $\circ$ segundo sexo diante da figura masculina.

Nessa perspectiva, incita-se a pensar sobre o discurso da mulher pesquisada (Girassol) que, mesmo estando formada em nivel superior, ainda permanece no espaço privado e seu esposo, no papel de macho da casa, aquele que - de acordo com ela - "veste as calças", no espaço público provendo o sustenta da família. Reflete-se que atualmente o fato de as mulheres falarem sobre as opressões que sofrem, ou até mesmo denunciá-las, consiste em politizar as esferas, uma vez que as condições de subordinação deixaram de ser privadas e passam a ser públicas e questionadas, publicizadas como se refere esta análise.

Desse modo, problematiza-se, por meio deste, a assertiva decorrente do senso comum de que "em briga de marido e mulher, não se mete a colher", porém, se mete a colher sim, e os movimentos feministas trazem à tona essa reconfiguração dos papéis sociais, em que não se considera natural um homem ser o provedor e, portanto, ter direitos sobre a mulher como se fosse sua propriedade, que se questionam os atos de subordinação e opressão vivenciados diariamente por muIheres, que nesta pesquisa, se evidenciam nas relações conjugais.

Os movimentos feministas levam para as mulheres a perspectiva de questionar e tornar os fatos públicos, em uma perspectiva de libertação, de modo a perceberem que, para amar e ser feliz, não precisam se calar diante das opressões, não precisam ouvir que são putas, vagabundas e esposas, como xingamentos, muito menos se sentirem culpadas por não agradar o marido ou por apanhar deste. 
É preciso falar dos fenômenos relacionados à área privada, na qual os fatos referentes às mulheres casadas tornam-se públicos e problematizados. É preciso pensar em um feminismo que abarque todas as mulheres, inclusive as casadas que, muitas vezes, sofrem em silêncio, diante da atual conjuntura social que, infelizmente, impõe modelos de como ser o que se chama de "mulher de verdade". É nessa perspectiva que Rosaldo (1979) sugere que só será possivel uma igualdade quando os homens adentrarem no espaço doméstico e as mulheres no espaço público, afirmando a necessidade de "[...] combinar objetos políticos com questões utópicas [...]" (p. 60).

A história da educação brasileira para mulheres revela o retrato de mudanças e resistências ao longo do tempo sobre modelos atribuídos. De acordo com Villela (2000), no século XIX, com a criação de escolas normais, surgiu a preocupação em formar professores para o que seria uma nova educação; nesse processo existiam exigências como saber ler e escrever e a maior delas centrava-se na boa morigeração, havendo mecanismos de exclusão do saber e currículos diferenciados, de modo que os meninos aprenderiam a Geometria, enquanto as meninas a Educação Doméstica. Esse currículo diferenciado era relacionado ao papel social atribuido às mulheres, no âmbito particular, no qual os costumes patriarcais enfatizavam preconceitos quanto a sua capacidade intelectual com relação aos homens.

Uma cultura fortemente enraizada que se sustentou por muitos anos, até os movimentos sociais emergirem em busca de direitos, como o movimento feminista - que ganhou força na década de 1960 -, questionando as visões androcêntricas e sexistas ${ }^{7}$, nos vários cenários sociais, trazendo à tona a história das mulheres, construída por elas.

Ainda sobre a análise do discurso da entrevistada, percebe-se que a mesma já passou por violência física, como também por violência simbólica, sendo chamada pelo marido de feia, gorda, e também utilizava termos pejorativos de insulto e inferiorização.

Vale ressaltar que a Lei $N^{0} 11.340$, de 7 de agosto de 2006, conhecida como Lei Maria da Penha refere-se a todas as formas de violência contra a mulher. $O$ Art. $5^{\circ}$ informa que "[...] configura violência doméstica e familiar contra a mulher qualquer ação ou omissão baseada no gênero que lhe cause morte, lesão, sofrimento físico, sexual ou psicológico e dano moral ou patrimonial" (BRASIL, 2006). O Art. $7^{\circ}$ da mesma Lei destaca que são formas de violência contra a mulher,

Art. $7^{\circ}$ - São formas de violência doméstica e familiar contra a mulher, entre ou- 
tras:

I - a violência física, entendida como qualquer conduta que ofenda sua integridade ou saúde corporal;

II - a violência psicológica, entendida como qualquer conduta que the cause dano emocional e diminuição da auto-estima ou que lhe prejudique e perturbe o pleno desenvolvimento ou que vise degradar ou controlar suas ações, comportamentos, crenças e decisões, mediante ameaça, constrangimento, humilhação, manipulação, isolamento, vigilância constante, perseguição contumaz, insulto, chantagem, ridicularização, exploração e limitação do direito de ir e vir ou qualquer outro meio que lhe cause prejuizo à saúde psicológica e à autodeterminação;

III - a violência sexual, entendida como qualquer conduta que a constranja a presenciar, a manter ou a participar de relação sexual não desejada, mediante intimidação, ameaça, coação ou uso da força; que a induza a comercializar ou a utilizar, de qualquer modo, a sua sexualidade, que a impeça de usar qualquer método contraceptivo ou que a force ao matrimônio, à gravidez, ao aborto ou à prostituição, mediante coação, chantagem, suborno ou manipulação; ou que limite ou anule o exercício de seus direitos sexuais e reprodutivos;

IV - a violência patrimonial, entendida como qualquer conduta que configure retenção, subtração, destruição parcial ou total de seus objetos, instrumentos de trabalho, documentos pessoais, bens, valores e direitos ou recursos econômicos, incluindo os destinados a satisfazer suas necessidades;

$\checkmark$ - a violência moral, entendida como qualquer conduta que configure calúnia, difamação ou injúria. (BRASIL, 2006).

Percebe-se que a violência contra a mulher vai além da violência física, e, neste artigo os discursos remetem a todos os tipos de violência que diz respeito a física, psicológica, sexual, patrimonial e moral. A pena varia de 2 a 6 anos de prisão dependendo do caso e da violência sofrida.

Nesse cenário de violências e sonegação de direitos, as entrevistadas proferem sobre a relação sexual como parte do contrato social (casamento), ao qual Amarilis (pseudônimo da terceira entrevistada) descreve como uma obrigação conjugal.

\section{Sexo Conjugal: Depósito de Espermas?}

Neste tópico, a priori, solicita-se que o leitor preste atenção no discurso que se segue, tentando não se emocionar/indignar!

Eu casei com 16 anos, só no civil mesmo, e aí ganhei algumas lingeries e acabei comprando algumas coisas também, mas ai quando eu usava uma calcinha fio dental ou qualquer coisa do tipo, ele ficava bravo e dizia que era coisa de puta. Eu me depilava, me perfumava toda e vestia a melhor lingerie, ia para o quarto me sentindo linda, mas quando chegava lá ele me fazia tirar e apagar a luz, dizendo que era coisa de vagabunda, que mulher casada não fazia isso e que odiava esse tipo de coisa. Uma vez ele cuspiu na minha cara e mandou deixar de ser puta. E mesmo depois dos xingamentos ele exigia que eu "desse" a ele porque essa era a minha obrigação. Já triste e magoada, minha vagina ficava seca e sem beijos ou qualquer carinho, ele começava a colocar e me machucava muito, eu ficava calada aguentando e ele ainda reclamava que eu era seca. Ai em meio a tudo aquilo, eu ainda tentava melhorar e gemia ou me 
mexia e ai ele gritava para me calar, chamando de porra e as vezes me batia forte, e aí eu ficava ali parada aguentando a dor, as vezes lágrimas caiam do rosto, eu disfarçava para ele não perceber, naquela agonia eu só conseguia pensar que logo iria acabar e pedia a Deus que ele gozasse logo e saísse de cima de mim. Mas isso já faz alguns anos, com o tempo passei a ter coragem de falar com ele que me machucava e que não era bom, ele continua sem me beijar, diz que isso é coisa de adolescente e que casado não precisa disso, mas já tenta melhorar, hoje não dói tanto, as vezes até consigo gozar, outras vezes não sinto nada, mas algo me incomoda, toda vez que acaba me sinto mal como um depósito de espermas. Às vezes eu choro e passo horas no banho tentando me limpar, e quando eu saio do banheiro ele ainda me pergunta se gozou muito e se foi bom, eu apenas balanço a cabeça e aceito que sou uma mulher casada que nunca saberá o que é esse sexo gostoso que vejo nos vídeos ou que minhas amigas falam com tanto entusiasmo. (AMARÍLIS).

Por meio desse relato a mulher conta com detalhes sua vida sexual com o marido, em um discurso que, muitas vezes traça, características de estupro, por meio da violência simbólica e física. Uma violência que a leva aceitar a sua condição de esposa, depósito de espermas e que nunca saberá o que é um orgasmo. Por meio dessas palavras percebe-se o poder da subordinação e inferiorização da mulher em sua relação conjugal, um privado que se torna público por meio deste artigo, possibilitando questionar essas práticas e levar a outras mulheres à desnaturalização da opressão conjugal.

Ouvir e ver relatos como esse na sociedade atual levam a perceber a necessidade e importância do feminismo, educação pelo fim do sexismo e estudos de gênero que transgridam as regras e que apresentem para as mulheres possibilidades de ir de encontro a subordinações tão desumanas quanto estas aqui analisadas.

mundo está em pleno século XXI, a dita época da pós-modernidade, mas ainda enganchados em processo de congelamento do século XVIII, no período da colonização quando o país ainda nem era República, mas que por meio da educação já se separavam os modelos de mulheres aceitas na dita sociedade de bem.

Assim como evidencia Mary Del Priori (2011), em seu polêmico livro sobre as histórias intimas, no qual a mesma nos convida a pensar sobre as formas de dominação, subordinação e transformação da sexualidade, assim como o conceito de público e privado, o conceito de moral construído, os manuais confeccionados pela igreja, de como o casal deveria ter relações sexuais com o viés apenas de procriação etc. A escritora, através de um resgate histórico, faz refletir sobre as mudanças ao longo do tempo, afirmando que tudo possui seu contexto e época, a fim de evitar anacronismos.

Nesta análise, não se afirma que nada mudou ao longo dos séculos, mas que ainda há respingos da história educativa/corretiva destinada às mulheres, e que ainda há aquelas que sofrem com os modelos impostos, mulheres que choram e que entendem que merecem uma vida melhor, mas que não conseguem se libertar da opressão do patriarcalismo que ainda perdura na sociedade atual. 
Narvaz (2010) aponta o interesse pelo desnudamento da produção ideológica no que se refere ao gênero e às posições sociais atribuídas a homens e mulheres, os quais precisam ser questionados e desnaturalizados, como a explicação simplista baseada no biológico, uma vez que ser homem ou mulher são características individuais, políticas e culturais, nunca naturais. Faz-se necessário desnaturalizar o gênero binário e problematizar as identidades fixas e heteronormativas, pensando na mulher casada que vive no dito modelo ideal, subserviente da ordem masculina.

A entrevistada (Amarilis) faz perceber a necessidade de continuar na luta e de levar o feminismo e a educação sexual, na sua função de empoderamento para essas mulheres que, entrelaçadas no seio emocional e amoroso, vivem a vida à mercê do parceiro, sempre agradando e nunca sendo agradada.

Diaz e Cruz (2015) afirmam que essa realidade sexista, machista e extremamente masculina é diariamente reforçada dentro da educação escolar através da divisão histórica entre corpo e mente, de modo que o corpo é disciplinado e controlado na escola, dentro de um processo naturalizador atribuído a masculino e feminino, e aqueles que fogem a esses modelos são excluídos.

Louro (2010) argumenta acerca de uma pedagogia da sexualidade, centrada no controle do desejo, criando ou reproduzindo modelos, destacando o normal e questionando o diferente. A educação escolar presente no século XXI, que ainda reproduz modelos de feminilidade e masculinidade, assim como padrões e modelos de ser mulher, ensinando a sentar "direito", separando cores, brinquedos e espaços, reproduzindo através de brincadeiras e brinquedos a subserviência do feminino para com o masculino. Com base em estudos como estes e experiências de formação e atuação professoral, pode-se dizer que existe uma deficiência no ensino escolar atual, considerando que ainda há modelos estabelecidos para meninos e meninas, bem como resistências familiares, culturais e estatais que tornam a transversalização de gênero uma emergência, evidenciando a necessidade de estudos nesse campo, a fim de quebrar as barreiras estabelecidas como modelos.

Torna-se nebuloso falar que, atualmente, ainda existem mulheres casadas que são proibidas de sentir prazer e estão fadadas a exercer o seu papel apenas de reprodutora, mãe e dona de casa. Mulheres que no século XXI ainda vivenciam práticas decorrentes dos séculos XIX e XX, quando uma mulher sentir prazer sexual era considerado uma anomalia ou doença, e o homem como o único que poderia manifestar prazer, buscando as mulheres de fora do lar para tal prática.

É importante argumentar, que aqui não há um posicionamento contra o casamento, mas contra as opressões disfarçadas de modelos de mulher ideal, dona de casa e feliz, opressões que barram as mulheres de se firmarem sua condição de seres humanos de vontades e de direitos. Propôs-se, por meio desta análise, problematizar a vida de mulheres casadas, aplaudidas no seio social em que o homem ainda é o centro em uma constante hierarquia de poder atribuído aos sexos. 
Nesse percurso, enfatiza-se a fala de Saffioti (1987) quando leva a questionar a quem serve esse poder, uma vez que dele derivam prejuizos para as mulheres que se transformam no objeto de prazer do homem, como para ele que terá seu prazer reprimido pelo poder; mesmo assumindo que o patriarcado pesa mais para as mulheres, a supracitada autora propõe um feminismo de humanização e igualdade, a fim de pensar em melhores condições de vida para ambos os lados, considerando que o poder é sempre oposto ao prazer. Trata-se de um jogo de instrumentalização onde ninguém é feliz, vivendo em um constante desprazer.

\section{Considerações Finais}

É preciso falar das mulheres no cenário do privado e o entrelaço de opressões, violências, emoções, dependências (econômicas e psicológicas), imaginário social e amores que as colocam na condição de subalterna, criando uma relação de poder patriarcalista que não traz prazeres para nenhum dos lados, opressões que martirizam e fazem sofrer, que levam os seres humanos a uma constante infelicidade.

Por meio desta análise, é possivel perceber que ainda perdura, na atualidade, o imaginário social que atribui modelos de ser mulher (santas e putas), porém o modelo de mulher aplaudido como o "ideal" que é ser casada, também constitui opressões conjugais que ferem os direitos das mulheres na qualidade de seres humanos e cidadãs.

Nessa perspectiva, ressalta-se que esta pesquisa se propôs a refletir sobre as nuanças da opressão patriarcal conjugal, chegando ao fim com a certeza da importância dos movimentos feministas e de gênero que problematizem os padrões e que não se calem diante das subordinações e violências sofridas diariamente por mulheres em todos os campos sociais.

Enfatiza-se, por meio deste, a necessidade de trazer para a academia a esfera privada, tornando-a pública e problematizada, um feminismo que abarque todas as mulheres no contexto histórico, cultural, social, econômico e emancipador.

Faz-se necessário uma revolução que não é de lutas armadas, mas mental, de mudanças de valores e paradigmas, em termos de rever os papéis e as estruturas sociais estabelecidas. A proposta do feminismo nesse sentido é de democratizar e humanizar as relações, pensando nas possibilidades de rupturas, desvinculando-se e desnaturalizando o simulacro social atual. A possibilidade dada é de reinvindicação, uma constante processualidade, pois, tem-se a consciência de que não é algo que fica pronto de uma hora para outra, considerando que se torna emergente mudança de mentalidades, que são culturais, possuindo paradigmas a serem quebrados e problematizados. Um viés primordial para tal propósito diz respeito à educação como um processo abrangente de construção e empoderamento de mentalidades no que se refere ao feminismo e práticas de democratização e equidade. 
Portanto, esta pesquisa, para além de análise de gaveta, pode funcionar como denúncia e pedido de socorro, no que diz respeito a políticas emergenciais de transversalização de gênero e empoderamento feminino na atualidade.

\section{Referências}

BRASIL, Lei n ${ }^{0} 11.340$, de 7 de agosto de 2006. (Lei Maria da Penha). Cria mecanismos para coibir a violência doméstica e familiar contra a mulher, nos termos do $\S 8^{\circ}$ do art. 226 da Constituição Federal, da Convenção sobre a Eliminação de Todas as Formas de Discriminação contra as Mulheres e da Convenção Interamericana para Prevenir, Punir e Erradicar a Violência contra a Mulher; dispõe sobre a criação dos Juizados de Violência Doméstica e Familiar contra a Mulher; altera o Código de Processo Penal, o Código Penal e a Lei de Execução Penal; e dá outras providências. Diário Oficial da União - seção 1, Brasilia, DF, Ano CXLIII No-151, p. 1-3, ISSN 1677-7042

CARVALHO, Maria Eulina Pessoa de et al. Direitos humanos das mulheres e das pessoas LGBTQI: inclusão da perspectiva da diversidade sexual e de gênero na educação e na formação docente. João Pessoa. Editora da UFPB, 2016. 74p.

DEL PRIORI, Mary. Histórias íntimas - sexualidade e erotismo na história do Brasil. 2a reimpressão, São Paulo: Editora Planeta do Brasil, 2011.

DIAS, Alfrancio Ferreira; CRUZ, Maria Helena Santana. A produção/reprodução do corpo generificado na escola. Cadernos de Pesquisa, v. 22, n.3, pp.25-41, 2015; ISSN 2178-2229.

FOLLADOR, Kellen Jacobsen. A mulher na visão do patriarcado brasileiro: uma herança ocidental. Revista fato \& versões n.2 v.1, p.3-16, 2009; ISSN 1983-1293.

FOUCAULT, Michel. A ordem do discurso: Aula inaugural no Collége de France, pronunciado em 2 de dezembro de 1970. Tradução de Laura Fraga de Almeida Sampaio - 18 ed- São Paulo: . Janeiro de 2009.

LOURO, Guacira Lopes. Mulheres na sala de aula. In: DEL PRIORE, Mary (Org.). História das mulheres no Brasil. 9. ed. São Paulo: Contexto, 2008. p.443-481.

LOURO, Guacira Lopes. Pedagogias de sexualidade. In: LOURO, Guacira Lopes (org.). O corpo educado: pedagogias da sexualidade 3. ed. Belo Horizonte: Autêntica, 2010.

MARQUES, Helena. Feminismo, empoderamento e sororidade. Entenda o significado dessas expressões. In: Pureople. 8 de março de 2018. Disponível em 
<http://www.purepeople. com.br/ noticia/empoderamento-feminismo-e-sororidade-veja-a-importancia-dessas-palavras-no-dia-da-mulher_a218729/1> Acesso em: 10 jul. 2018.

MEIRINHOS, Manuel. OSÓRIO, Antônio. O estudo de caso como estratégia de investigação em educação. Eduser: revista de educação, Vol. 2(2), 2010; e-ISSN 1645-4774. Disponivel em <https://bibliotecadigital.ipb.pt/bitstream $/ 10198 / 3961 / 1 / 0 \% 20$ estudo\%20de\%20 caso\%20como\%20 estrat\%C3\%A9gia\%20de\%20 investiga\%C3\%A7\%C3\%A30\%20 em $\% 20$ educa \%C3\%A7\%C3\%A3o.pdf>. Acesso em: 10 jul. 2018.

MEYER, Dagmar Estermann. PARAíSO, Marlucy Alves (Org.). Metodologias de pesquisas pós críticas em educação. Horizonte: Mazza Ediçõ̃es, 2012.

NARVAZ, Martha Giudice. Gênero: para além da diferença sexual. Revista da literatura Aletheia, n. 32, maio/gosto, 2010, p. 174-182. Universidade Luterana do Brasil, 2010; e-ISSN 1981-1330. Disponivel em: < http://www.redalyc.prg/ articulo.oa?id=11502083014>.

PROST, Antoine. As questões do historiador. In: PROST, Antoine. Doze lições sobre a História. Belo Horizonte: Autêntica, 2014, p.53-73.

ROSALDO, M. Zimbalist. A cultura e a sociedade: uma revisão teórica. In: ROSALDO et al. A mulher a cultura e a sociedade. São Paulo: Paz e Terra. 1979.

SAFIOTTI, Heleith I. B. O poder do macho. São Paulo: Moderna. 1987.

VENTURA, M. M. O estudo de caso como modalidade de pesquisa. Revista SoCERJ, v. 20, n. 5, p. 383-386, 2007; ISSN 2177-6042. Disponivel em: <http:// www.polo.unisc.br/portal/upload/

com_arquivo/o_estudo_de_caso_como_modalidade_de_pesquisa.pdf> Acesso em: 20 ago. de 2016.

VILLELA, Heloisa de O. S. O mestre-escola e a professora. In: LOPES, Eliane Marta Teixeira; FARIA Filho, Luciano Mendes e VEIGA, Cynthia Greive. 500 anos de educação no Brasil. Belo Horizonte: Autêntica, 2000, p. 95-134.

Recebido em julho de 2018.

Aprovado em setembro de 2018. 